p. 240). Yet not the gods themselves, in Homer's time, were aware of such a guide. It must be remembered, however, that the axis of the earth's rotation pointed, 2800 years ago, towards a considerably different part of the heavens from that now met by its imaginary prolongation. The precession of the equinoxes has been at work in the interval, slowly but unremittingly shifting the situation of this point among the stars. Some 600 years before the Great Pyramid was built, it was marked by the close vicinity of the brightest star in the Dragon. But this in the course of ages was left behind by the onwardtravelling pole, and further ages elapsed before the star at the tip of the Little Bear's tail approached its present position. Thus the entire millennium before the Christian era may count for an interregnum as regards Pole-stars. Alpha Draconis had ceased to exercise that office; Alruccabah had not yet assumed it.

The most ancient of all the constellations is probably that which Homer distinguishes as never-setting (it then lay much nearer to the pole than it now does). In his time, as in ours, it went by two appellations-the Bear and the Wain. Homer's Bear, however, included the same seven bright stars constituting the Wain, and no more ; whereas our Great Bear stretches over a sky-space of which the Wain is only a small part, three of the striding monster's far-apart paws being marked by the three pairs of stars known to the Arabs as the "gazelle's springs." How this extension came about, we can only conjecture; but there is evidence that it was fairly well established when Aratus wrote his description of the constellations. Aratus, however, copied Eudoxus, and Eudoxus used observations made-doubtless by Accad or Chaldean astrologers-above 2000 B.C. ${ }^{1}$ We infer, then, that the Babylonian Bear was no other than the modern Ursa Major.

But the primitive asterism-the Seven Rishis of the old Hindus, the Septem Triones of the Latins, the Arktos of Homer-included no more than seven stars. And this is important as regards the origin of the name. For it is impossible to suppose a likeness to any animal suggested by the more restricted group. Scarcely the acquiescent fancy of Polonius could find it "backed like a weasel," or "very like a whale." Yet a weasel or a whale would match the figure equally well with, or better than, a bear. Probably the growing sense of incongruity between the name and the object it signified may have induced the attempt to soften it down by gathering a number of additional stars into a group presenting a distant resemblance to a four-legged monster.

The name of the Bear, this initial difficulty notwithstanding, is prehistoric and quasi-universal. It was traditional amongst the American-Indian tribes, who, however, sensible of the absurdity of attributing a conspicuous protruding tail to an animal almost destitute of such an appendage, turned the three stars composing it into three pursuing hunters.

The same constellation figures, under a divinified aspect, with the title Otawa, in the great Finnish epic, the "Kalevala." Now, although there is no certainty as to the original meaning of this word, which has no longer a current application to any terrestrial object, it is impossible not to be struck with its resemblance to the Iroquois term Okowari, signifying "bear," both zoologically and astronomically (Lafitau, op. cit., p. 236). The inference seems justified that Otawa held the same two meanings, and that the Finns knew the great northern constellation by the name of the old Teutonic king of beasts.

It was (as we have seen) similarly designated on the banks of the Euphrates; and a celestial she-bear, doubtfully referred to in the Rig-Veda, becomes the startingpoint of an explanatory legend in the Râmâyana (De Gubernatis, "Zoological Mythology," vol. ii. p. IO9).

${ }^{2}$ According to Mr. Proctor's calculation. See R. Brown, "Eridanus River and Constellation," p. $\hat{3}$.
Thus, circling the globe from the valley of the Ganges to the great lakes of the New World, we find ourselves confronted with the same sign in the northern skies, the relic of some primæval association of ideas, long since extinct.

Extinct even in Homer's time. For the myth of Callisto (first recorded in a lost work by Hesiod) was a subsequent invention-an effect, not a cause-a mere embroidery of Hellenic fancy over a linguistic fact, the true origin of which was lost in the mists of antiquity.

There is, on the other hand, no difficulty in understanding how the Seven Stars obtained their second title of the Wain, or Plough, or Bier. Here we have a plain case of imitative name-giving-a suggestion by resemblance almost as direct as that which established in our skies a Triangle and a Northern Crown. Curiously enough, the individual appellations -still current for the stars of the Plough, include a reminiscence of each system of nomenclature-the legendary and the imitative. The brightest of the seven, $a$ Ursæ Majoris, the Pointer nearest the Pole, is designated Dubhe, signifying, in Arabic, "bear"; while the title Benetnasch-equivalent to Benaten-Nasch, "daughters of the bier"-of the furthest star in the plough-handle, perpetuates the lugubrious fancy, native in Arabia, by which the group figures as a corpse attended by three mourners.

A. M. CleRKE

(To be continued.)

\section{RAINBAND OBSERVATIONS AT THE BEN NEVIS OBSERVATORY}

R AINBAND spectroscopy is one of the extra subjects taken up at the Ben Nevis Observatory, along with the usual meteorological routine. At every hour, when there is sufficient light, the intensity of the rainband is observed and recorded, and now, the mean daily rainband forms one of the items in the Ben Nevis weather report in the daily newspapers. The scale in use is practically the same as that used by Dr. Mill, of the Granton Marine Station, and described by him in a paper to the Royal Society of Edinburgh (Proc. R.S.E., 1882-84). This scale is in the spectrum itself-a great convenience -being the Fraunhofer lines E, $b$, and $\mathrm{F}$ of the solar spectrum. After a preliminary set of observations had been made, in various types of weather, for the purpose of determining the relative intensity of these lines, a numerical value was given to each, namely, to $\mathrm{E}, 2$; to $b$, 4 ; and to F, 7. After a little practice, it is quite easy to estimate the values less than 2, which often occur, and the values above 7 , which very seldom occur. With this scale, the intensity or darkness of the rainband and $\mathrm{D}$ line taken together is compared, and the numerical value of its scale-equivalent entered in the register. The instrument used is one of Hilger's rainband pocket spectroscopes, and the part of the sky always observed is between $30^{\circ}$ and $40^{\circ}$ above the south-western horizon.

The results obtained in 1885 were communicated to the Scottish Meteorological Society, and are published in their Journal for 1886 (see NATURE, vol. xxxiii. p. 622). In I 886, over 3000 observations were made, and the relative frequency with which each number of the scale was observed will convey an idea of the intensity of the rainband on Ben Nevis. The percentage of observations of each number is as follows :-

Rainband

Percentage

$\begin{array}{llll}0 & 1 & 2\end{array}$

The mean of all the observations gives a rainband of I" 7 Now at sea-level, according to Dr. Mill, the rainband is seldom or never less than $\mathrm{E}$, that is, than 2 on our scale. Hence the mean rainband on the Ben is about equal to the minimum at sea-level. About 80 per cent. of these observations were made when the Ben was enveloped in fog or mist. The only effect fog or mist has upon the 
rainband is that its intensity is the same in every possible direction, whereas in clear weather, as is well known, it is generally greatest at the horizon and least at the zenith. But as the rainband in fog or mist has been found to be equal to that which is observed in clear weather at an altitude of $30^{\circ}$ or $40^{\circ}$-the altitude of that part of sky always observed-the presence or absence of fog and mist has been ignored in working up the observations.

In forecasting the weather for the surrounding lowlevels, the rainband observed here, together with similar observations at Fort William, would probably be of great value, but its forecasting power for the summit alone is limited. The lower values generally show indications of rain several hours before it comes on, but the higher values simply indicate a continuation of the heavy rainfall by which they are Invariably accompanied. To show that the rainfall increases with the successive numbers of the scale, the mean hourly rainfall has been computed, for each scale value, from the rainfall of the three hours and twelve hours after noon. For the observations of I 885 , the mean daily rainband was used. In 1886 , each individual observation was taken into account, and, for each number of the scale, the mean rainfall was computed from the rainfall of the three hours after each observation. As the results differ in some respects, they are here given for each year separately :-

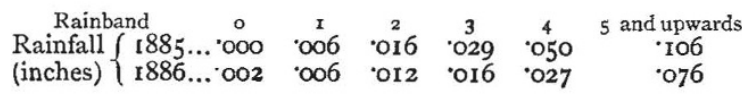

Owing to the fewness of observations of the numbers 5,6 , and 7 , they have been grouped together. The higher values are followed by a rainfall which is proportionally far too high, owing, no doubt, to the fact that these higher values are only observed during the passage of cyclonic disturbances laden with moisture from the Atlantic, when a great amount of this moisture only comes into the spectroscopic field in a condensed state, when it is forced to ascend so as to pass the summit, and consequently does not affect the rainband, but causes a very heavy rainfall. The moisture that ascends the mountain, not being detected below by the spectroscope here, is a constant source of disparities in the agreement of rainband and subsequent rainfall. The fact that our mean rainband is not greater than $1 \%$, and that the amounts of rainfall were, for $1885,146.497$ inches, and for 1886 , 107.847 inches, clearly indicates that a great part of our rainfall is due to the condensation of the moisture that is forced up from below the level of the summit.

In comparing rainband with subsequent rainfall, the temperature of the air at the time of observation, as wel as the variation in the temperature, must be taken into account. With the view of ascertaining the relations between rainband, subsequent rainfall, and temperature, the mean hourly rainfall for the three hours after an observation, for each number of the rainband scale, and for every $5^{\circ}$ of temperature from $15^{\circ}$ to $50^{\circ}$, has been calculated, and the results for rainbands of values I, 2, and 3; are as follows :-

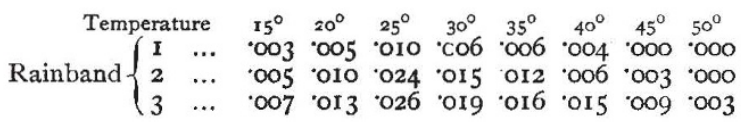

The means for temperatures of $25^{\circ}$ and upwards show that for any one rainband, when the temperature rises the rainfall decreases, and when the temperature falls the rainfall increases. The results being as yet only tentative, it cannot be definitely stated by how much the mean hourly rainfall increases or decreases per degree of fall or rise in the temperature, for any one value of the rainband. The means for temperatures below $25^{\circ}$ seem to indicate that a fall in the temperature causes a decrease in the rainfall, which is not at all probable. If it be the case that low temperatures do not affect the absorbing powers of aqueous vapour, which is not likely, the smal amount of rainfall at these low temperatures may be due to the necessarily unsatisfactory measurements of precipitation obtained from the rain-gauge when the temperature is below $32^{\circ}$. In truth, snowfall and rainfall as measured by the rain-gauge, can hardly be compared with each other. For a full account of these and other questions of rainfall here, see Mr. Omond's articles and also Mr. Buchan's "Meteorology of Ben Nevis" in the Journal of the Scottish Meteorological Society for the last two years.

The mean rainbands at the different temperatures are :-

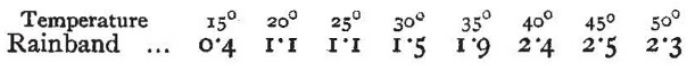

The greatest number of observations at any one temperature was 724 at $30^{\circ}$, and the least 35 at $50^{\circ}$.

The reason why so many observations were made in 1886 was to find whether there was any daily variation in the rainband. That there is a slight variation will be seen from the following results, which are for the summer months only, viz. :-

$$
\begin{aligned}
& \begin{array}{cccccccc}
\text { Hour } & 6 & 7 & 8 & 9 & \text { 10 } & \text { II } & 12 \text { noon } \\
\text { Rainband } & I \cdot 4 & I^{\circ} \cdot 4 & I^{\circ} \cdot 6 & I^{\prime} \cdot 5 & \text { I.6 } & \text { I.6 } & I^{\circ} 7
\end{array} \\
& \begin{array}{lllllllll}
\text { Temperature } 32^{\circ} \cdot 0 & 32^{\circ} \cdot 3 & 32^{\circ} \cdot 7 & 33^{\circ} \cdot 2 & 33^{\circ} \cdot 5 & 34^{\circ} \cdot 0 & 34^{\circ} \cdot 4
\end{array} \\
& \begin{array}{ccccccc}
\text { Hour } & 13 & 14 & 15 & 16 & 17 & 18 \\
1.7 & 1 \cdot 0 & 1 \cdot 8 & 1 \cdot 7 & 1.8 & 1 \cdot 7
\end{array} \\
& \begin{array}{lrrrrrrr}
\text { Temperature } & 34^{\circ} \cdot 8 & 35^{\circ} \cdot 0 & 35^{\circ} \circ & 34^{\circ} 9 & 34^{\circ} \cdot 7 & 34^{\circ} \cdot 3
\end{array}
\end{aligned}
$$

The rise in the rainband from 6 a.m. till 3 p.m. following the temperature, points to the cause of this daily variation as being the expansion of the lower atmosphere by the rising temperature, and the consequent raising of the vapour above the level of the Ben. This is almost the same cause to which Mr. Buchan ascribes the rise in the barometric pressure for the same daily period. Prof. Piazzi Smyth says that the rainband does not increase for a rise of temperature at sea-level, because the total quantity of vapour over the place of observation is pretty constant (Journal Scot. Met. Soc., vol. v.). But over this summit the quantity of vapour is not constant, but varies, and the rainband varies with it.

Remarkable variations in the rainband occur in the course of a single day, often amounting to 3 , and sometimes to 5 and 6 . On March 26, I886, when a cyclone was passing to the north of the Observatory, the rainband varied from 6 at 10 a.m., to 3 at 12 noon, and to 1 at 5 p.m. The strongest mean for any one day was 8 on January I, I 886 , while a mean of 0 has frequently occurred. On December 18 , I 885, a rainband, estimated at 12, was observed on the rising sun-this was one of the noted "fore-glow" mornings. In anticyclonic weather, which is characterised by great dryness of the air, with all the clouds at lower levels, a strong rainband is always obtained from the layer of air close over the clouds, in summer, when not a trace is detected at the usual height of observation ; but in similar weather in winter the rainband is often entirely absent, even over the clouds. It is noteworthy that on days with little or no rainband, when not actually looking at the sun, the spectrum as a whole is darker than usual, and on days with strong rainbands, the parts of the spectrum not occupied by lines are brighter than usual. In a certain type of weather, when the rain-gauge completely fails to record the precipitation, the rainband always indicates the presence in the air of the vapour which gives it. This occurs when snowcrystals are deposited with low temperatures and strong winds, as described in NATURE (vol. xxxi. p. 532). The importance of rainband observations will be greatly increased when similar series can be undertaken at the sealevel simultaneously with those on the summit of Ben Nevis.
A. RANKIN 